\title{
Multiscale adaptive simulations of concrete carbonation taking into account the evolution of the microstructure
}

\author{
Claus-Justus Heine ${ }^{\dagger}$, Christian A. Möller ${ }^{\ddagger}$, Malte A. Peter ${ }^{\ddagger}$, Kunibert G. Siebert $^{\dagger}$ \\ ${ }^{\dagger}$ Institut für Angewandte Analysis und Numerische Simulation, Fachbereich Mathe- \\ matik, Universität Stuttgart, Pfaffenwaldring 57, 70569 Stuttgart, Germany, \\ claus-justus.heine@ians.uni-stuttgart.de,kg.siebert@ians.uni-stuttgart.de \\ ${ }^{\ddagger}$ Institut für Mathematik, Universität Augsburg, Universitätsstraße 14, 86159 Augs- \\ burg, Germany, c.moeller@math.uni-augsburg.de, malte.peter@math.uni-augsburg.de
}

\section{ABSTRACT}

Concrete carbonation is a chemical degradation mechanism compromising the service life of reinforced concrete structures. Using a homogenization approach to upscale the associated reaction-diffusion system given in a porous medium, whose microstructure undergoes an evolution in time, an effective macroscopic limit model is obtained. To lower the complexity of numerical simulations further, an efficient adaptive finite element scheme for the limit problem is presented. The approach is generally applicable to reaction-diffusion problems in porous media.

\section{INTRODUCTION}

Concrete carbonation takes place in the pores of concrete, which are partially saturated with water that clings to the pore walls, and involves reaction, diffusion, precipitation and dissolution. Atmospheric carbon dioxide $\left(\mathrm{CO}_{2}\right)$ enters the concrete through the air-filled pores and dissolves in the pore water. There, it reacts with dissolved constituents of the cement paste, most importantly with calcium hydroxide $\left(\mathrm{Ca}(\mathrm{OH})_{2}\right)$. This causes a lowering of the $\mathrm{pH}$, facilitating the corrosion of the steel reinforcements and, consequently, leads to a severe reduction of the service life of the structure. The dominant carbonation reaction is usually assumed as

$$
\mathrm{CO}_{2}(a q)+\mathrm{Ca}(\mathrm{OH})_{2}(a q) \longrightarrow \mathrm{CaCO}_{3}(a q)+\mathrm{H}_{2} \mathrm{O} .
$$

The produced calcium carbonate $\left(\mathrm{CaCO}_{3}\right)$ precipitates quickly to the solid matrix. Detailed surveys on the carbonation problem were carried out, for instance, by Bier (1988); Bunte (1994); Chaussadent (1999); Kropp (1995) and, from a more mathematical point of view, by Muntean (2006).

Many researchers have tried to find simple formulas for the advancement of the carbonation in a concrete sample (cf. Sisomphon, 2004; Muntean et al., 2005, for 
discussions of these). There are also some works with respect to modelling carbonation with reaction-diffusion systems, most notably Meier et al. (2007b); Muntean (2006); Peter et al. (2008); Saetta et al. (1993); Steffens et al. (2002). In the homogenization context, it is also worth noting the article Samson et al. (1999), where ion diffusion in concrete is modelled using spatial averaging, and Meier et al. (2007a), where a twoscale model for a simple carbonation scenario is proposed.

An important feature of concrete carbonation is that the carbonation reaction causes a change of the microstructure of the porous concrete in at least two ways. First, the reactant $\mathrm{Ca}(\mathrm{OH})_{2}$ takes up considerably less volume than the product $\mathrm{CaCO}_{3}$. This results in a permanent reduction of the pore-air volume. Second, water is produced in the carbonation reaction, which induces a (usually) temporary reduction of the pore-air volume and an increase of the volume of the reaction medium. While it seems that the latter effect is of considerable importance only in accelerated carbonation tests (as opposed to carbonation under natural atmospheric conditions), cf. Muntean et al. (2005), the first effect is always important because it permanently slows down the diffusion of $\mathrm{CO}_{2}(g)$ to the reaction zone and, in turn, reduces the speed of the overall carbonation process, also cf. Meier et al. (2007b). A detailed discussion of these effects and their impact on the progress of carbonation can be found in Muntean et al. (2005). The purpose of this contribution is to combine the modelling results of Peter \& Böhm (2009) and the structure of the algorithm ASTFEM developed for the heat equation by Kreuzer et al. (2012) to present an efficient multiscale numerical model of concrete carbonation taking into account the change of the microstructure.

\section{THE MODEL}

It was derived by Peter \& Böhm (2009) that a homogenized (macroscopic) model for concrete carbonation is as follows,

$$
\begin{aligned}
\partial_{t} j^{\mathrm{a}} & =-\left|Z^{\mathrm{w}}\right| C^{\mathrm{m}} C^{\mathrm{H}} R u v^{\mathrm{w}}, & & x \in \Omega, \\
\partial_{t}\left(\left(j^{\mathrm{a}}\left|Z^{\mathrm{a}}\right|+\left|Z^{\mathrm{w}}\right|\right) u\right)-\nabla \cdot\left(j^{\mathrm{a}} D^{\mathrm{a}} P^{\mathrm{a}} \nabla u\right) & =-\left|Z^{\mathrm{w}}\right| m^{\mathrm{u}} R u v^{\mathrm{w}}, & & x \in \Omega, \\
\left|Z^{\mathrm{w}}\right| \partial_{t} v^{\mathrm{w}} & =-\left|Z^{\mathrm{w}}\right| C^{\mathrm{H}} m^{\mathrm{v}} R u v^{\mathrm{w}}, & & x \in \Omega, \\
-j^{\mathrm{a}} D^{\mathrm{a}} P^{\mathrm{a}} \nabla u \cdot \nu & =C^{\operatorname{ext}}\left(u-u^{\mathrm{ext}}\right), & & x \in \partial \Omega, \\
u(\cdot, 0)=u_{0}, v^{\mathrm{w}}(\cdot, 0) & =v_{0}^{\mathrm{w}}, j^{\mathrm{a}}(\cdot, 0)=1, & & x \in \Omega,
\end{aligned}
$$

$t \in S$, where $u=u(x, t)$ is a combined concentration of $\mathrm{CO}_{2}$ in pore air and pore water, $v^{\mathrm{w}}=v^{\mathrm{w}}(x, t)$ is the concentration of $\mathrm{Ca}(\mathrm{OH})_{2}$ in pore water and $j^{\mathrm{a}}=j^{\mathrm{a}}(x, t)$ is the pore-volume factor describing the reduction of pore-air volume by the carbonation process. The parameters of the model are: $\left|Z^{\mathrm{a}}\right|$ - initial pore-air volume, $\left|Z^{\mathrm{w}}\right|$-initial pore-water volume, $C^{\mathrm{m}}$ - volume-reduction factor, $D^{\mathrm{a}}$ - diffusivity of $\mathrm{CO}_{2}$ in air, $P^{\mathrm{a}}-$ initial tortuosity of pore air, $C^{\mathrm{H}}-$ Henry constant, $R$ - reaction constant, $m^{i}, j \in\{\mathrm{u}, \mathrm{v}\}$ - molar weights, $u^{\text {ext }}-$ external $\mathrm{CO}_{2}$ concentration, $C^{\text {ext }}-$ Robin constant, $u_{0}, v_{0}^{\mathrm{w}}-$ initial concentrations.

Typical simulations results of the algorithm discussed in what follows are 

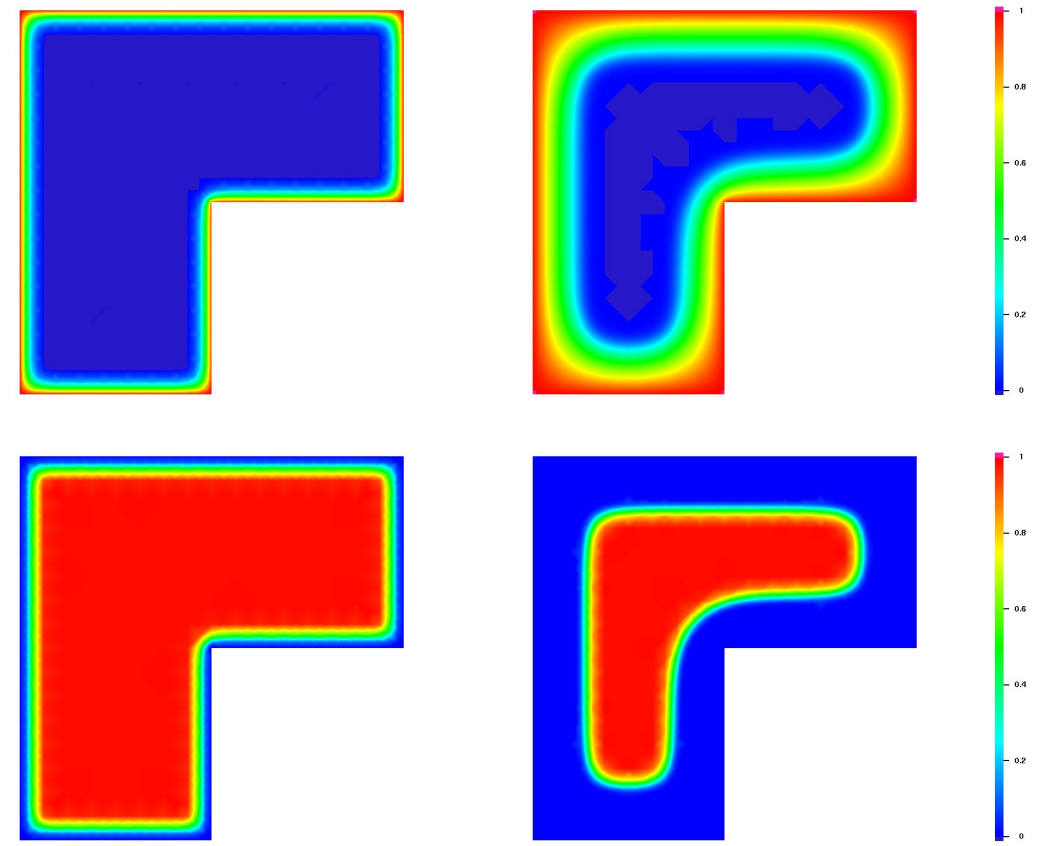

Figure 1. Concentration of $\mathrm{CO}_{2}$ (top) and $\mathrm{Ca}(\mathrm{OH})_{2}$ (bottom) after one year (left) and 16 years (right) of carbonation for an L-shaped cross-section.

shown in Figures 1 and 2 (the physical parameters are stated below). It can be clearly seen that the carbonation reaction is confined to a narrow zone, which progresses into the material. This moving reaction zone is a typical feature of fast-reaction-slowdiffusion scenarios and it is evident that adaptive numerical methods capable of local refinement and coarsening are required for the efficient simulation of such processes.

Since the process of concrete carbonation usually involves narrow reaction zones moving slowly through the material, we are motivated to use an adaptive algorithm; see also Schmidt et al. (2005) where adaptive simulations based on a simple reaction-diffusion model are presented. More precisely, the need for adaptivity is evoked by the fact that the sharp reaction front exhibits steep gradients of the involved concentrations while, in other parts of the material, the concentrations vary only slightly or not at all. In order to resolve numerically such reaction fronts, a high mesh resolution is needed in the area of fronts. This can be easily provided by employing a uniformly fine mesh. A drawback of uniform meshes are large computing times with high memory consumption. However, a uniformly fine mesh is not needed since slowly varying concentrations can easily be approximated on a relatively coarse mesh. Using meshes that are locally fine close to reaction fronts and relatively coarse in other areas drastically reduces computational costs while still providing nearly the same accuracy compared to uniform grids. On top of this, the time step size is adapted to the temporal behavior of the true solution.

An important quantity for engineering purposes is the carbonation depth, 


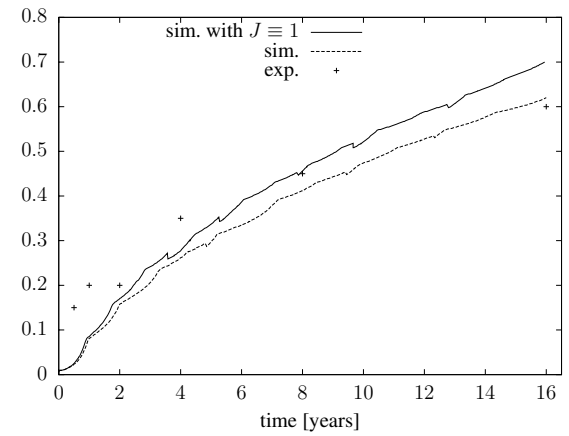

Figure 2. Carbonation depth at the left side of the sample for the presented model accounting for an evolution of the microstructure (dotted line) compared to experimental data (symbols) and with constant microstructure, i.e. assuming $j^{\mathrm{a}} \equiv 1$, (solid line).

i.e. the depth the carbonation reaction zone has penetrated into the concrete sample after a given amount of time. Typically, it is defined as the level set $v^{\mathrm{w}} / v_{0}^{\mathrm{w}}=0.1$ (following Steffens et al., 2002). In Figure 2, the predicted carbonation depth is plotted in comparison to experimental data of Wierig (1984) (long-term exposure out of doors under roof). It can be seen that good approximation of experimental data is achieved. Furthermore, Figure 2 also compares the results with a simulation, where the evolution of the microstructure is neglected, i.e. the pore-volume factor $j^{\text {a }}$ is constantly set to unity, which is the case in most carbonation models in the literature. It can be clearly seen that this neglect results in an overestimation of the carbonation depth toward the end of the time interval and, thus, it is important to account for the evolution of the microstructure. Moreover, as isolines of concentration are used to generate model output, a highly accurate capturing of the concentration profiles is particularly important.

\section{DESCRIPTION OF THE ADAPTIVE METHOD}

The discretization starts with a semi-discretization in space. Instead of solving the resulting three coupled nonlinear ordinary differential equations simultaneously by, e.g., an implicit Euler method in combination with Newton's method, we use a semi-implicit discretization in time as follows. A linearization of the coupled system of ordinary differential equations in each time step makes it possible to solve for $v^{\mathrm{w}}$ and $j^{\text {a }}$ explicitly using $u$ from the previous time step and substitute the result into the remaining linear equation for $u$ at the new time, thus leading to a decoupled discretization. It turns out that the additional approximation in the decoupled discretization is reflected in the results only very mildly while increasing the performance of the algorithm drastically.

For the space-time adaptation strategy, we use the following heuristic approach. The adaptation of the spatial mesh based on ASTFEM (Adaptive Space Time Finite Element Method, cf. Kreuzer et al., 2012) is with respect to the $\mathrm{CO}_{2}$-concentration as 
this is the only quantity satisfying a partial differential equation. On the other hand, it is obvious that the strongest need for spatial adaptation comes from the large gradients in $\mathrm{Ca}(\mathrm{OH})_{2}$-concentration (and of the pore-volume factor). While these facts seem to be incompatible at first, it turns out that a very elegant circumvention of this problem can be accomplished by distributing non-uniformly the (local-in-time) tolerances driving the adaptive method. This results in meshes, which are very well suited for the $\mathrm{Ca}(\mathrm{OH})_{2}$-concentration as well. It is important to note that such an alternative weighting of the tolerances is in-line with rigorous error control (for the associated linear system) while typical other approaches (e.g. error indicators based on $\mathrm{Ca}(\mathrm{OH})_{2}$ gradients) are not.

\section{NUMERICAL RESULTS}

In this section, we present some computational results of applying the method described above to solve the carbonation problem implemented using the finite element toolbox ALBERTA, cf. Schmidt \& Siebert (2005). We anticipate that the presented results clearly indicate that we tremendously profit from applying adaptive methods in the simulation of concrete carbonation.

In order to be able to compare the simulation results to experimental data, we restrict our considerations to a particular type of concrete and specific exposure conditions. We assume a piece of concrete based on Ordinary Portland Cement to be exposed to natural atmospheric conditions and compare the simulations with experimental data. To fix ideas, we use the experimental data of Wierig (1984) for PZ1 concrete with a water-to-cement ratio of 0.6 exposed "out of doors under roof".

The values of the model parameters refer to an L-shaped cross-section of an Ordinary Portland Cement concrete sample with a side length of $5 \mathrm{~cm}$ under natural exposure conditions. Our simulations cover a period of 16 years and begin shortly after the curing time. The parameter values are taken from Papadakis et al. (1989); Steffens et al. (2002) and they resemble those used in Peter \& Böhm (2009). After curing, we assume no $\mathrm{CO}_{2}$ inside the concrete sample and that $0.693 \mathrm{~g} / \mathrm{cm}^{3}$ of $\mathrm{Ca}(\mathrm{OH})_{2}$ is available to the carbonation reaction. We assume an ambient $\mathrm{CO}_{2}(g)$-concentration resembling natural atmospheric conditions, $u^{\text {ext }}=0.54 \cdot 10^{-6} \mathrm{~g} / \mathrm{cm}^{3}$ and we take the empirical value $C^{\text {ext }}=10^{3} / \mathrm{d}$. We do not calculate the initial macroscopic diffusion tensor but use the empirical value $D^{\mathrm{a}} P^{\mathrm{a}}=2.2 \cdot 10^{-3} \mathrm{~cm}^{2} / \mathrm{d}$ instead. For the reaction rate, we use the empirical value $R=500 \mathrm{~mol} \cdot \mathrm{cm}^{3} /\left(\mathrm{g}^{2} \mathrm{~d}\right)$, the molar weights are $m^{\mathrm{u}}=44 \mathrm{~g} / \mathrm{mol}$ and $m^{\mathrm{v}}=74 \mathrm{~g} / \mathrm{mol}$ and the Henry constant is $C^{\mathrm{H}}=0.81$. The volume fractions are $\left|Z^{\mathrm{a}}\right|=0.18$ and $\left|Z^{\mathrm{w}}\right|=0.1$ and we use $\left|Z^{\mathrm{a}}\right| C^{\mathrm{m}}=40.36$, which corresponds to a reduction of pore-air volume by $21 \%$ (cf. Peter \& Böhm, 2009, for a detailed discussion of the parameter associated with the change in pore-air volume).

Figure 3 shows the concentration of $\mathrm{CO}_{2}$ after one year, four years, and 16 years in the top row. The middle row depicts the concentration of $\mathrm{Ca}(\mathrm{OH})_{2}$ at the same times and the bottom row shows the pore-volume factor, which ranges from 0.79 (cor- 

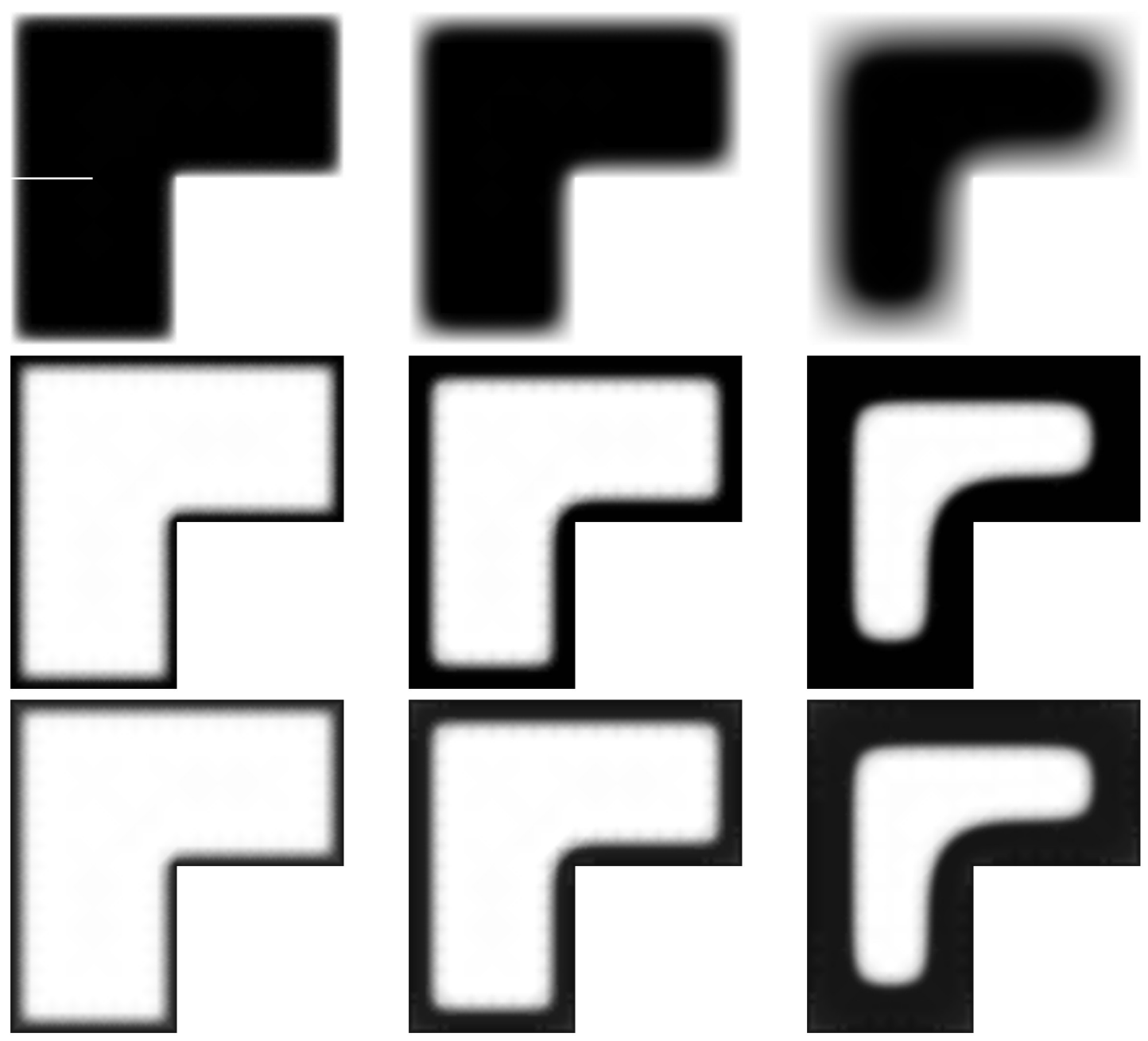

Figure 3. Solution to the carbonation problem. $\mathrm{CO}_{2}$ (top) and $\mathrm{Ca}(\mathrm{OH})_{2}$ (middle) concentrations as well as pore-volume factor (bottom) after 1 year (left), 4 years (middle), and 16 years (right). In the top and the middle row, black indicates value 0 and white indicates value 1 . In the bottom row, black indicates 0.79 and white indicates 1. 

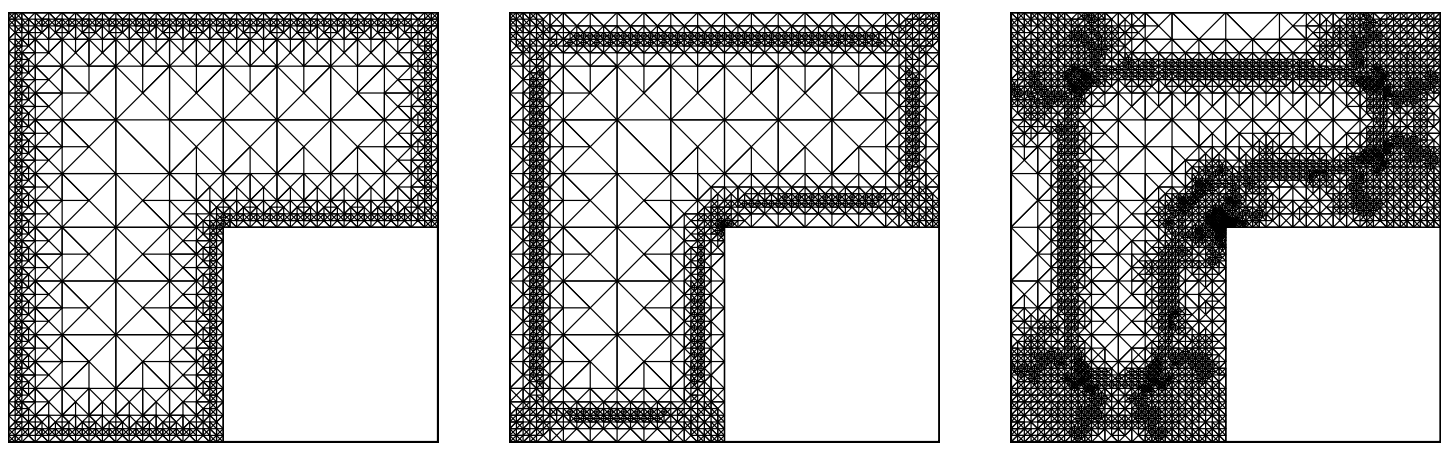

Figure 4. Meshes corresponding to the decoupled discretization with decreasingly distributed tolerances. (The meshes correspond to the concentration profiles of Figure 3).

responding to the desired reduction of the pore-air volume by $21 \%$ ) to 1 . Whereas all concentrations are plotted in a normalized way, i.e. $u / u^{\text {ext }}$ and $v^{\mathrm{w}} / v_{0}^{\mathrm{w}}$, we use dimensional quantities with respect to space and time. The long edges of the "L-shape" are five centimeters, the short edges are 2.5 centimeters. Note that the white line in the top left plot indicates the position of the cut used for the carbonation depth in Figure 2.

We observe, that the steep gradient in the $\mathrm{CO}_{2}$-concentration after one year is greatly smoothened after 16 years. Opposed to that, the concentration of $\mathrm{Ca}(\mathrm{OH})_{2}$ exhibits steep gradients throughout the time interval. This implies that the bulk of the carbonation reaction is concentrated on a narrow zone which advances into the concrete with time. This coincides with other simulation results, cf. Meier et al. (2007b); Papadakis et al. (1989); Peter \& Böhm (2009).

The solutions obtained by employing the decreasing distribution of the tolerance are resolved well for all times; the corresponding meshes are depicted in Figure 4. In particular, we observe that the most interesting zone, i.e. the reaction zone, is resolved very well.

We emphasize again that whereas the reaction zone is characterized by steep gradients of the $\mathrm{Ca}(\mathrm{OH})_{2}$-concentration, the gradients of the $\mathrm{CO}_{2}$ concentrations in this zone are quite moderate. Since the employed adaptive procedure adapts the mesh with respect to the $\mathrm{CO}_{2}$-concentration, we cannot expect a sufficient resolution of the reaction zone using equidistributed tolerances. Nevertheless, this deficiency is eradicated using the decreasing distribution of tolerances.

A detailed account on the algorithm and more extensive results will be presented in a forthcoming publication.

\section{References}

BIER, T. A. 1988 Karbonatisierung und Realkalisierung von Zementstein und Beton. $\mathrm{PhD}$ thesis, University of Karlsruhe. 
BunTE, D. 1994 Zum Karbonatisierungsbedingten Verlust der Dauerhaftigkeit von Aussenbauteilen aus Stahlbeton. PhD thesis, Technical University of Braunschweig.

Chaussadent, T. 1999 États de lieux et réflexions sur la carbonatation du beton armé. Tech. Rep. LCPC OA29. Laboratoire Central de Ponts et Chaussées, Paris.

Kreuzer, C., Möller, C. A., Schmidt, A. \& Siebert, K. G. 2012 Design and convergence analysis for an adaptive discretization of the heat equation. IMA J. Numer. Anal. 32, 1375-1403.

KROPP, J. 1995 Relations between transport characteristics and durability. In Performance criteria for concrete durability (ed. J. Kropp \& H. K. Hilsdorf), RILEM Report 12, pp. 97-137. E \& FN SPON.

Meier, S. A., Peter, M. A. \& BöHM, M. 2007a A two-scale modelling approach to reaction-diffusion processes in porous materials. Comp. Mat. Sci. 39 (1), 29-34.

Meier, S. A., Peter, M. A., Muntean, A. \& Böhm, M. $2007 b$ Modelling and simulation of concrete carbonation with internal layers. Chem. Engng Sci. 62 (4), 1125-137.

Muntean, A. 2006 A moving-boundary problem: modeling, analysis and simulation of concrete carbonation. $\mathrm{PhD}$ dissertation, University of Bremen. Cuvillier.

Muntean, A., Meier, S. A., Peter, M. A., Böhm, M. \& Kropp, J. 2005 A note on the limitations of the use of accelerated concrete-carbonation tests for servicelife predictions. Berichte aus der Technomathematik 05-04. ZeTeM, University of Bremen.

PAPAdAkis, V. G., VAyenas, C. G. \& FARdis, M. N. 1989 A reaction engineering approach to the problem of concrete carbonation. AIChE J. 35 (10), 1639-1650.

Peter, M. A. \& BöHM, M. 2009 Multi-scale modelling of chemical degradation mechanisms in porous media with evolving microstructure. SIAM Multisc. Mod. Sim. 7 (4), 1643-1668.

Peter, M. A., Muntean, A., Meier, S. A. \& BöHM, M. 2008 Competition of several carbonation reactions in concrete: a parametric study. Cem. Concr. Res. 38 (12), 1385-1393.

Saetta, A. V., Schrefler, B. A. \& Vitaliani, R. V. 1993 The carbonation of concrete and the mechanism of moisture, heat and carbon dioxide flow through porous materials. Cem. Concr. Res. 23 (4), 761-772.

Samson, E., Marchand, J. \& Beaudoin, J. J. 1999 Describing ion diffusion mechanisms in cement-based materials using the homogenization technique. Cem. Concr. Res. 29 (8), 1341-1345. 
Schmidt, A., Muntean, A. \& BöHm, M. 2005 Numerical experiments with selfadaptive finite element simulations in $2 \mathrm{~d}$ for the carbonation of concrete. Report 05-01, ZeTeM University of Bremen .

SCHMidT, A. \& SiEBERT, K. G. 2005 Design of adaptive finite element software. The finite element toolbox ALBERTA. Lecture Notes in Computational Science and Engineering 42. Springer.

Schmidt, A., Siebert, K. G., Heine, C.-J., Köster, D. \& Kriessl, O. 2009 ALBERTA: An adaptive hierarchical finite element toolbox. http: //www.alberta-fem.de/, version 1.2.2.

SisOMPHON, K. 2004 Influence of pozzolanic material additions on the development of the alkalinity and the carbonation behaviours of composite cement pastes and concretes. PhD thesis, Technical University Hamburg-Harburg.

Steffens, A., Dinkler, D. \& Ahrens, H. 2002 Modeling carbonation for corrosion risk prediction of concrete structures. Cem. Concr. Res. 32 (6), 935-941.

WIERIG, H.-J. 1984 Longtime studies on the carbonation of concrete under normal outdoor exposure. In Proceedings of the RILEM, Hannover University, pp. 239-249. 